\title{
LIBERALISMO Y PROFESIÓN DOCENTE
}

\author{
CARLOS MOUGÁN RIVERO
}

Universidad de Cádiz

\author{
PALABRAS CLAVE ADICIONALES \\ Ética, Democracia, Postmodernidad, Educación, \\ Virtudes Cívicas.
}

\section{ADDITIONAL KEYWORDS}

Ethics, Democracy, Postmodernity, Education, Civics Virtues.

RESUMEN. En general, la tarea docente ha estado comprometida, de acuerdo con una moral laica de orientación racional, con la divulgación del conocimiento. Bajo el paradigma de la concepción liberal e ilustrada, se entendía que dicha tarea contribuía a la mejora del individuo y a la consecución de un mundo mejor. La crisis postmoderna de la educación liberal ha supuesto el desencantamiento de la ética de la profesión docente y ha suscitado reacciones que suprimen o minimizan su compromiso con la promoción de valores cívicos. Frente a ello se defiende el carácter político de la función docente y se argumenta a favor de la necesidad de redefinir este perfil profesional desde una perspectiva que acentúa la importancia que el sistema de enseñanza bajo control público y el profesorado tienen para el mantenimiento y la profundización en la democracia

\begin{abstract}
The teaching task, according to rational secular moral, has traditionally been a compromise with knowledge. It was considered, under the liberal and enlightment conception, that such a task helped to the individual moral improvement and to the achievement of a better world. The postmodern crisis of liberal education has implied the disenchantment of the teaching task ethics and it has caused reactions which minimize or eliminate the compromise with the promotion of civic values. We defend the political character of the teaching task and the necessity to redefine the professional profile to highlight the importance of the public school system and the teachers to contribute to the maintenance and to go deeply in democracy.
\end{abstract}

E-mail: carlos.mougan@uca.es

Revista Internacional de Sociología (RIS)

Tercera Época, N ${ }^{\circ}$ 34, Enero-Abril, pp. 135-166, 2003. 
RIS

REVISTA INTERNACIONAL DE SOCIOLOCIA

№ 34, Enero-Abril, 2003

CARLOS MOUGÁN RIVERO

\section{INTRODUCCIÓN}

Se pretende, en el presente trabajo, poner de manifiesto los argumentos o razones que nos permiten aclarar cuál es el compromiso moral que supone la tarea docente. El análisis parte de aceptar que las creencias y convicciones de cada uno condicionan de manera decisiva la forma de actuar. Las personas actuamos de acuerdo con nuestros intereses, nuestras expectativas (dinero, gustos, prestigio, ..), pero también de acuerdo con nuestra interpretación de la finalidad o el propósito al que nuestra acción sirve, lo que implica una cierta concepción acerca de la sociedad, del ser humano y, más genéricamente aún, de la realidad. No es necesario que estas interpretaciones, que estas concepciones de la sociedad y el papel que nuestra acción supone en ellas sean explícitas, ni elaboradas conscientemente, pero en cualquier caso, están ahí proporcionando un marco de significatividad y orientación a nuestra actuación. Así pues, comprender las acciones de cualesquiera de los agentes que intervienen en el sistema educativo exige tener en cuenta el proyecto cultural en el se inscriben. De otra manera, se asume que la acción docente sólo puede ser explicada por referencia a la función a la que cree servir, y ésta se enmarca en una manera genérica de entender la tarea educativa en el seno de nuestra sociedad. Si esto es cierto, entonces se debe admitir que la acción docente adquiere sentido en un marco interpretativo en el que las cuestiones referidas a los modos de vida buena, y a los modos de organización social justa han de ocupar un lugar destacable. Y este es nuestro campo de trabajo, la ocupación con la profesión docente desde el punto de vista de la filosofía moral y política, desde la reflexión sobre las maneras buenas de vivir y de organizar la sociedad, y cómo éstas se relacionan con el mundo de la educación. Esto es, se trata de una perspectiva no centrada en lo educativo, como si de un subsistema encerrado en sí mismo se tratase, sino de ponerla en conexión con las interpretaciones, con las teorías sociales y políticas de las que se nutre.

Nuestro punto de partida se desprende del siguiente principio metodológico: el desarrollo de la teoría moral y política tiene su correlato en las distintas perspectivas o enfoques sobre la educación moral y sobre la responsabilidad que al docente le compete en su tarea. Se sostendrá que el desarrollo y evolución de la filosofía política arroja luz sobre las transformaciones que se han ido produciendo en la manera en que podemos interpretar la misión del docente en la sociedad, y que los problemas planteados en el pensamiento político liberal tienen su traducción en las dificultades que encontramos al pensar la tarea del profesional de la educación. La tesis que se defiende es que la acción docente ha tenido sentido en la medida en que ha estado enmarcada en una narrativa, una interpretación ética y política, que la justificaba de manera racional y de la cuál extraía su fuerza. Esta narrativa se fue constituyendo en la época moderna al hilo de una teoría moral y política, la teoría liberal, de la que se desprendió un modelo o ideario educativo que podemos considerar encuadrado bajo el rótulo de "educación libe- 
\begin{tabular}{rr} 
R IS \\
LIBERALLSMO Y PROFESIÓN DOCENTE \\
\hline
\end{tabular}

ral". Este modelo interpretativo alcanza su máximo esplendor bajo el paradigma del pensamiento ilustrado y alimenta una parte importante de las concepciones y expectativas aún hoy válidas para una parte importante del profesorado. Pues bien, este paradigma se sustentaba sobre una serie de presupuestos que, una vez puestos en cuestión, han dejado en entredicho la narrativa moderna sobre la educación y el papel de la profesión docente en la sociedad. Las respuestas a esta situación que han minimizado la responsabilidad moral del docente son inadecuadas para el tipo de sociedad en el que vivimos, e incorrectas desde una perspectiva democrática. En resumen, se sostendrá que de la misma manera que el pensamiento político liberal tiene dificultades que le obligan a reformular su propia teoría, también debemos repensar en el ámbito de la educación, el papel, la función y el compromiso moral del docente.

\section{EL DOCENTE EN LA TRADICIÓN LIBERAL RACIONALISTA}

Desde un punto de vista ético, el docente ha entendido, tradicionalmente, que el compromiso que exigía su profesión, de acuerdo con una moral laica de orientación racional ${ }^{1}$, ha estado vinculado con la divulgación del conocimiento. Bajo el paraguas de lo que podemos denominar como "educación liberal", el profesorado ha solido entender que su tarea se limitaba a transmitir el conocimiento, la cultura o la razón en la forma en que cada época ha establecido el desarrollo científico, en el sentido más amplio del término. El paradigma de la educación liberal ha servido de explicación y de justificación de la labor docente en una tarea que se ha caracterizado a sí misma como humanizadora, como posibilitadora del despliegue de la humanidad misma. Ahora bien, ¿qué quiere decir "educación liberal"?

Como algunos autores han coincidido en señalar, la elaboración del concepto de educación liberal viene de la mano del desarrollo de la teoría política liberal que representa una parte importante del legado moderno en el seno de la tradición occidental. De hecho, en los más grandes pensadores de la tradición liberal, a pesar de las diferencias existentes entre ellos, podemos encontrar las líneas maestras del concepto moderno de educación liberal: Locke, Kant y Mill. Así, Thiessen ha señalado que "los valores centrales del liberalismo incluyen libertad, autonomía, individualismo, igualdad, perdida de confianza en la autoridad y la tradición, tolerancia, racionalidad crítica, ciencia y creencia en el progreso" (Thiessen, 1993: 36); y estos serán asimismo los valores nucleares de la educación liberal.

\footnotetext{
'Aunque nos referimos de manera genérica a la profesión docente excluimos de nuestra consideración, por razones metodológicas, la docencia con fines netamente doctrinarios, en especial de carácter religioso.
} 
RIS

Aun cuando el desarrollo de esta idea se debe a la época moderna algunos autores, que han estudiado con detenimiento el concepto de educación liberal y su desarrollo, como Kimball (1993) o Hirst (1982), encuentran las raíces en la tradición de pensamiento iniciada por Sócrates y Platón, pues es a la época griega donde debemos remitir la idea de que el conocimiento es la actividad peculiar del ser humano, lo que le distingue y corresponde a su verdadera naturaleza. En lo que a nuestro tema se refiere, lo peculiar de dicha interpretación es que la búsqueda del conocimiento racional es, al mismo tiempo, la garantía de la consecución del bien, de la vida buena y de la perfección y felicidad del ser humano. La educación, en tanto que forma de acceso al conocimiento racional, suponía para los griegos la realización del ser humano. De este modo, educación racional era sinónimo de educación moral. La adquisición del conocimiento científico y la educación ética y política eran dos caras del mismo proceso. La educación, destinada al conocimiento de lo verdadero y real, tiene por objeto el conocimiento mismo, el desarrollo del espíritu, "un valor que nada tiene que ver con consideraciones utilitarias o profesionales" (Hirst op. cit., 364). Aparece así la primera caracterización del concepto liberal de educación, aquél que queda formulado estrictamente en términos del conocimiento del hombre. Se trata de que, para el espíritu liberal, la educación está destinada al servicio del conocimiento y del desarrollo de la razón. Esto significa liberarse de los prejuicios, de las convenciones sociales, de los valores establecidos por el vulgo para acceder al reino de la verdad que trasciende la particularidad cultural. Si esta enseñanza es sinónimo de libertad y racionalidad, la opuesta sería aquella forma de educación que se hace con otro propósito que no sea el del conocimiento puro. La educación no liberal es aquella que se hace desde una perspectiva parcial, destinada no al desarrollo mismo del espíritu y del conocimiento sino en aras de fines sesgados o particularistas. Es la que está contaminada por los prejuicios, o la que tiene como fundamento la religión, la que se deja guiar por el peso de la tradición y de las costumbres, o la que aparece dirigida por intereses prácticos.

Siguiendo esta línea de interpretación, Thiessen (1995) ha puesto de manifiesto que el rasgo más notable del concepto moderno de educación liberal es el énfasis en la libertad, en el sentido de "liberar de", dejar atrás los condicionamientos de la tradición y de las estructuras a priori. Este concepto liberal de educación es el que está presente en los autores ilustrados, vinculándose ahora la libertad con el ejercicio de la racionalidad, el escepticismo crítico y el individualismo. Es posiblemente Kant, con su desarrollo del concepto de autonomía, el ejemplo más notable de esta línea de pensamiento. Para Kant, pensar racionalmente es pensar de acuerdo con principios universales de justificación racional, principios que, por tanto, escapan a los condicionamientos sociales, culturales e históricos. Por ello, requiere de la liberación de las trabas externas que impiden el ejercicio de la razón de acuerdo con sus propias pautas. La Ilustración y el pensamiento autónomo requieren libertad. Liberada de la presión del despótico orden social y político, la 
razón se desarrollaría irremisiblemente, y los sujetos se convertirían en dueños de su propio progreso. La humanidad habría acabado la época de su minoría de edad y la razón se convertiría en la guía de la vida individual y social.

Como consecuencia de todo ello, una parte esencial del programa de la Ilustración incluía como tarea la educación, el cultivo de las capacidades que conduciría indefectiblemente a los seres humanos a la libertad moral y a la consecución de un orden social basado en principios racionales. La relación entre educación y emancipación forma parte de la gran narrativa que ha alimentado buena parte de las construcciones teóricas sobre la educación. Así, la idea de que mediante la educación los sujetos pueden liberarse de la superstición y de la ignorancia y que ello transformará tanto a los individuos como a las sociedades sigue siendo la idea directriz en torno a la cual se plantea, en el ámbito de lo educativo, el debate sobre la vigencia del pensamiento ilustrado.

Además, pensar la profesión docente desde este punto de vista liberal ilustrado exige tomar en consideración la perspectiva de J. S. Mill. Éste estaba preocupado por defender la libertad del individuo y su capacidad racional, frente a cualquier clase de imposición y adoctrinamiento sea de los padres o del Estado ${ }^{2}$. Rechazaba tanto la idea de que los padres pudieran convertir a sus hijos en extensiones de sí mismos como que el Estado impusiera a sus ciudadanos una determinada visión del bien. El objetivo, como en Kant, es la autonomía del sujeto, la capacidad del individuo para elegir por sí mismo su propio plan de vida. Mill estimó que ello sólo seria posible si se protegía la pluralidad de opiniones y la diversidad de modos de vida. Pues, cuando no se contrasta con argumentos los puntos de vista propios, la opinión degenera en dogmatismo y prejuicio, y allí donde no existen modos de vida alternativos el individuo no ejercita su capacidad de elección y sigue de manera acrítica los hábitos adquiridos irreflexivamente. Puesto que Mill aspiraba a una sociedad donde los individuos fueran capaces de pensar y elegir racionalmente por sí mismos, sostenía que el Estado debería salvaguardar el derecho de los niños a ser educados e informados, lo que constituye la base imprescindible para que la posibilidad de elegir con libertad sea efectiva. Desde este punto de vista, Mill defendió la obligatoriedad de la enseñanza, pero estimó que la misma se debía circunscribir a los datos, hechos y teorías, sin necesidad de que se les instruyera en cuál de las posiciones o teorías era la correcta o adecuada. Así, incluso llegó a defender una especie de prueba general que fuera objetiva y de la que, por tanto, se excluyeran las consideraciones personales, las creencias o posiciones de cada cuál, etc. Mill pensó que era posible y deseable una escuela liberada de prejuicios, una escuela en la que las opiniones y puntos de vista de cada uno quedaran aparcados a la puerta de la misma.

\footnotetext{
${ }^{2}$ Estas ideas las desarrolla J. S. Mill en el capitulo V de Sobre la libertad (1991).
} 
RIS

REVISTA INTERNACIONAL DE SOCIOLOGIA

№34, Enero-Abril, 2003

CARLOS MOUGÁN RIVERO

En definitiva, Mill quiere defender al ciudadano de las imposiciones doctrinarias y del dogmatismo con independencia de su origen: los padres, el estado o los profesores. Mill continúa la defensa educativa del desarrollo de la autonomía moral del individuo. No es que pensara, como pudiera parecer a primera vista, que el docente no está comprometido con unos valores morales, sino que éstos están subsumidos bajo unos presupuestos que son los que conforman la ideología ilustrada. La explicación es que tanto Kant como Mill entendían que el cultivo de la razón, el desarrollo de las capacidades lógico racionales, suponía la garantía de la consecución de la moralidad, y con ello el establecimiento de una sociedad más justa. En cuanto se suprimieran los obstáculos que dificultan el uso de la razón, en cuanto existiera libertad e intercambio de ideas, entonces los individuos se verían impelidos a usar la razón y, una vez que ello suceda, inexorablemente se tornarán capaces de trascender el horizonte de sus intereses particularistas. Por tanto, la educación liberal no rechaza la educación moral, sino que hace consistir a ésta en el desarrollo de las posibilidades lógico racionales del individuo. La educación liberal y racional debe ser una educación neutral, exenta de juicios particulares y de juicios sustantivos acerca de materias en las que pueda haber una disparidad de perspectivas y de puntos de vista. Es una educación liberada de compromisos sociales y políticos. Los valores morales han de ser relegados al ámbito de la privacidad y el profesional docente ha de excluir de su ejercicio sus propios puntos de vista. Así, la neutralidad moral, uno de los rasgos centrales de esta filosofía educativa, aparece como la garantía de la pluralidad y el respeto a las diferencias.

Como en la perspectiva de Mill se manifiesta con claridad, el docente ha de estar comprometido, ante todo, con la divulgación del saber, con la promoción del conocimiento, bajo el supuesto de que el compromiso con el conocimiento es un compromiso moral. En el paradigma de la educación liberal el conocimiento es sinónimo de libertad, racionalidad y moralidad. El profesorado, en los distintos niveles, es especialista en el área de conocimiento correspondiente y lo que su tarea docente le exige, desde el punto de vista ético, es dar cuenta del estado de los conocimientos del momento, en la confianza de que así está contribuyendo a un mundo mejor.

\section{CRISIS POSTMODERNA DEL CONCEPTO DE EDUCACIÓN LIBERAL}

Del mismo modo que el concepto de educación liberal se forja en paralelo a la consolidación del pensamiento moderno y liberal, la crisis del concepto tradicional de educación liberal viene de la mano de la quiebra del proyecto teórico ilustrado. Son varios los frentes de crítica o los supuestos que se desmoronan dentro del marco de lo que ha sido considerado por algunos como rasgos del pensamiento postmoderno. 


\section{A) El conocimiento}

Las formas del conocimiento no son el descubrimiento de realidades ya dadas y definitivamente establecidas. Por el contrario, en la medida en que el pensamiento contemporáneo ha insistido en que la experiencia es producto de una interacción entre nosotros y el mundo, ha puesto de relieve el carácter de construcción que tiene toda forma de conocimiento. Nuestros intereses, necesidades, etc.., guían nuestras formas de conocimiento. El cuestionamiento de la distinción entre hechos y valores ha sido una de las constantes de las distintas líneas de pensamiento, y significa el triunfo de la afirmación por la que el conocimiento aparece como una forma de poder, como forma de dominación de la realidad. En el ámbito de lo educativo, Foucault y sus discípulos han mostrado que los nuevos métodos de enseñanza no hacen sino refigurar nuevos modos de ejercicio del poder. Tras la huella dejada por Foucault en Vigilar y Castigar diversos estudios hacen aparecer al profesor, y a la cohorte de expertos que dominan el mundo de la educación, como los nuevos especialistas del alma humana entregados al diseño de individuos dóciles al modelo de sociedad consumista y capitalista, a la producción de lo que han llegado a denominar el homo clausus, el individuo narcisista que se diseña a sí mismo no según una voluntad de autonomía racional, sino en conformidad con las necesidades de nuestra sociedad de consumo. El profesor, asesorado por las disciplinas "psi" (psicólogos, pedagogos, psiquiatras), ya no es un divulgador del conocimiento, del bien y de la verdad sino un vehículo de control social. $\mathrm{La}$ educación es un proceso de control y domesticación de subjetividad humana para mantener el orden social vigente. Si para la tradición moderna liberal el conocimiento es sinónimo de libertad, esta línea de interpretación rescata otra idea moderna: el conocimiento es poder.

\section{B) EI sujeto}

Kant, y junto a él una buena parte de los autores modernos, entendió que las estructuras del sujeto eran innatas y universales. Los postmodernos han cuestionado la idea de la existencia de un yo universal, incambiable, unificado, con pleno control y conocimiento sobre lo que piensa, dice y hace. En general, la época postmoderna ha puesto de manifiesto que el yo está fuertemente influenciado por la cultura que nos rodea, que cambia con la cultura y es tan fragmentario como ella. La construcción de la identidad personal aparece, en nuestros días, como una realidad más problemática de lo que nunca fue. Mientras en otras épocas las señas de identidad se construían con pocos referentes, estables y sólidos, en la actualidad, la configuración de la identidad está hecha más que nunca a partir de fragmentos de identidades que aparecen como problemáticos y cambiantes. Ser mujer y católica, o minero y socialista, o maestro de ciencias naturales suponía que uno tenía una cierta narrativa acerca de las cosas, unos modelos con los que 
RIS

REVISTA INTERNACIONAL DE SOCIOLOGIA

№ 34, Enero-Abril, 2003

CARLOS MOUGÁN RIVERO

orientarse. Hoy somos muchas cosas y muchas de ellas ya no tienen puntos de referencia claros (¿qué significa ser mujer, o de izquierdas, ..?). No podemos agrupar a los individuos bajo alguna categoría porque participan de varias de ellas: religiosas, de género, étnicas, políticas, etc..

De otro modo, lo que los postmodernos han cuestionado es la idea de que existe una naturaleza humana esencial que precede a la historia y a las circunstancias culturales concretas. El yo ahistórico y no contingente es un mito. Para el postmodernismo el yo es una configuración descentrada de creencias y deseos, cuya autocomprensión está siempre mediada por los discursos aprendidos. Como no hay forma de apartarse de los mismos, puesto que siempre están configurados por los discursos históricos del momento, no hay ninguna naturaleza humana que descubrir.

Estos cambios en la interpretación acerca de cómo se construye la subjetividad humana resultan de gran significatividad en el ámbito de lo educativo, pues pone en cuestión la idea de que la educación consiste en el despliegue o desarrollo de habilidades y cualidades que están en el interior humano, y que sólo esperan a ser despertadas y desarrolladas. La transformación en la conformación de la subjetividad supone la quiebra de los ejes en torno a los cuales se articulaba el proceso socializador al que la escuela contribuía mediante la propagación y consolidación de roles. En definitiva, se trata de la crisis del proceso de socialización en el que la escuela tenía un papel determinante, y que abre las puertas a cuestionarse el tipo de individuo que la educación, y más en concreto la escuela, debe contribuir a forjar.

\section{C) Historia y progreso}

Se rechaza la idea kantiana de que el decurso de los tiempos nos conduce indefectiblemente hacia la consecución de un orden social justo, constituido por individuos racionales. De otro modo, no hay una razón universal que se desplegará y hará efectiva tan pronto como las condiciones externas lo permitan.

Así, se ha venido insistiendo en las ambivalencias de la sociedad postindutrial, globalizada, en el hecho de que los supuestos avances implican la aparición de nuevos peligros que ponen de manifiesto el carácter discutible del concepto de progreso. Por ejemplo, mejora nuestro conocimiento de la composición genética humana pero al mismo tiempo se abren las puertas a manipulaciones indeseables; aumenta exponencialmente la capacidad de gestión y almacenamiento de la información, pero ello abre posibilidades inéditas para el control de la vida privada de los individuos y genera nuevas desigualdades en las zonas que carecen de recursos materiales adecuados.

Desde el ámbito de lo educativo, la aparición de nuevas tecnologías se ve como algo positivo puesto que permite nuevas posibilidades pero, al tiempo, los nuevos medios de comunicación generan pérdida del sentido del esfuerzo, contribuyen al 
fortalecimiento de tendencias agresivas, destructoras o poco formativas, y, a decir de algunos, suponen un reto a la democracia misma al generar individuos apáticos y consumistas centrados en sí mismos y en las satisfacción de necesidades.

A la ruptura del vínculo entre progreso y desarrollo ha contribuido de manera especial la crítica ecologista, que ha erosionado, de manera definitiva, el supuesto por el que el cambio de las cosas es, necesariamente, hacia mejor y que el avance en los conocimientos consolidará un mundo y un futuro más libre y solidario.

La puesta en cuestión del concepto de progreso implica, al mismo tiempo, la crisis de la autoconcepción del docente que entendía que, por el mero hecho de trasmitir conocimientos, contribuía al proceso de emancipación humana. De esta manera, la profesión docente pierde el lugar privilegiado que la concepción de la educación liberal, racional e ilustrada había construido para él, y que le situaba en un plano moral superior a otras profesiones que carecían de este componente crítico emancipatorio.

\section{D) El pluralismo de la razón}

El pluralismo valorativo constituye un rasgo incontestable de nuestra realidad social. La perspectiva postmoderna supone el rechazo de que sólo hay una forma de moralidad compatible con el ejercicio de la razón. Las raíces griegas del ideal liberal se dejan ver en la afirmación de que el ejercicio de la razón lleva a los seres humanos al acuerdo. La exigencia universalista, inscrita en la naturaleza del ser humano, es central en toda la teoría política de la modernidad y aparece en la Ilustración bajo la forma de una filosofia de la historia que entiende el desarrollo histórico como una tendencia hacia la realización de una civilización guiada por principios racionales. Se trata de converger en una sola forma de vida, una civilización universal, racional y cosmopolita. La idea de progreso forma parte del núcleo de la tradición liberal racional.

Los postmodernos, por el contrario, entenderán que el pluralismo es un rasgo de nuestra razón, no un signo de debilidad de la misma. Esto sugiere la necesidad de pensar que lo central ya no es la elección racional sino la elección entre valores que son inconmensurables, que las diferencias en cuestiones valorativas son expresión de la naturaleza de la racionalidad humana. La coexistencia de puntos de vista, de modos de vida alternativos y discrepantes entre sí, no sólo deja de ser vista como una fuente posible de conflictos para el ser humano sino que, por el contrario, aparece ahora como una realidad enriquecedora. En el ámbito, más limitado, del nuevo pensamiento político liberal se ha querido salvar el núcleo de la teoría liberal sin tener que adoptar los compromisos morales u ontológicos propios del racionalismo ilustrado, para lo cual han hecho de la pluralidad y no de la autonomía el referente central del concepto de libertad en torno al cual ha de girar nuestra organización social. Así, bajo la óptica postmoderna el ideal de autonomía ilustrado es un ideal moral tan particularista y válido como pudiera 
serlo cualquier otro, singularmente los inspirados en visiones comprehensivas religiosas, con tal de que respeten las reglas de juego básicas de los sistemas democráticos constitucionales. Para los autores liberales postmodernos ${ }^{3}$, el liberalismo es una posición política que busca la posibilidad de la coexistencia pacífica. Se ha intentado, en este sentido, diferenciar el liberalismo como un proyecto moral, esto es, como una teoría que nos dice cuál es el mejor modo de vida humana, y el liberalismo político, un liberalismo que, en palabras de J. Shklar, tiene un exclusivo objetivo: "asegurar las condiciones políticas necesarias para el ejercicio de la libertad personal" (Shklar, 1989: 21).

Es quizá este punto el más relevante a la hora de pensar la tarea moral del docente en un régimen postmoderno pues, no en vano, el concepto de autonomía ha sido históricamente el objetivo primario que ha caracterizado al concepto moderno de educación, y el que ha distinguido a la educación liberal de otros modelos educativos, juzgados como doctrinarios desde dicha perspectiva. La consideración de la autonomía como un ideal moral particularista, y no como el ideal moral propio del ejercicio de la razón, supone, a nuestro entender, el golpe de gracia definitivo a la gran narrativa moderna sobre educación.

\section{RESPUESTAS QUE MINIMIZAN LA RESPONSABILIDAD MORAL DEL DOCENTE}

Las críticas postmodernas ponen en cuestión la vinculación entre el conocimiento y la idea de bien, y rompen los lazos que ligan a la educación con los proyectos sociales transformadores y con las construcciones utópicas de signo racional. La postmodernidad exige, por tanto, repensar el papel de la educación en la sociedad y, más en concreto, redefinir el rol moral del docente en tanto que agente transmisor de valores.

Cabe agrupar las respuestas a los interrogantes abiertos por la postmodernidad en diversos grupos. Tendríamos, en primer lugar, a todas aquellas posiciones que coinciden en minimizar el papel y la responsabilidad del profesor en la promoción de valores morales. Bajo esta perspectiva encuadraría tanto a los que consideran la profesión docente desde una perspectiva técnica desprovista de valores morales significativos, como a aquellos que consideran que este compromiso es mínimo.

\footnotetext{
${ }^{3}$ La obra más destacada en esta dirección es quizá Liberalismo Politico de J. Rawls (1996). A ello habría que añadir la de autores como R. Rorty, I. Berlin, J. Gray, etc.
} 
a) La defensa del individualismo. Una posible línea de respuesta a la crisis moral de la modernidad puede ser la radicalización del discurso liberal, acentuando su dimensión individualista. Puesto que no hay grandes construcciones teóricas, no hay relatos de salvación colectivos, lo que queda es el refugio en la individualidad y su capacidad automodeladora. La confianza en el sujeto, en su potencial y su posibilidad de creación tiene sus antecedentes modernos, pero se radicaliza en el discurso postmoderno perdiendo el horizonte moral y social del que gozaba en la época moderna. Aunque cuenta con pocos defensores en el ámbito intelectual español, las posiciones de corte libertario y antiautoritario tienen gran raigambre en el discurso práctico, en este caso de los docentes, y son en cualquier caso, posiciones significativas y orientativas en el plano de lo argumentativo.

La traducción de esta posición al problema de la transmisión de los valores morales en educación ha sido llevada a cabo por Flathman (1996). Este autor sostiene que "el objetivo de la educación es ensanchar la perspectiva de que los individuos formularán y serán capacitados para perseguir fines por sí mismos. De ahí se sigue que, como los estudiantes siguen concepciones definidas de sus objetivos, los educadores deberían adaptar su enseñanza para servir a las concepciones de sus estudiantes" (1996: 8). A su juicio, la educación liberal es aquella que está comprometida con la libertad y la individualidad, entendida como autorrealización, y que persigue la más amplia libertad posible de acción para la consecución de dicho fin. Por ello, la educación no ha de ser neutral sino que busca alimentar las capacidades y las diversas formas valiosas de entender la vida buena, fomentando con ello la diversidad y la pluralidad. La educación debe ser privada en varios sentidos. Así, por ejemplo, los educadores deben estar al servicio de las características individualizadoras de aquéllos a quienes sirven, por lo que los estudiantes deben tener un papel determinante en el carácter de sus experiencias educativas. "La educación puede y quizá debe ser tutorial pero tan poco paternalista como ello sea posible" (1996: 9). Como el propio Flathman señala, se trata de una interpretación cercana a las posiciones libertarias en educación, con mención concreta para Neill o Illich, a las que defiende en su pretensión de retar la idea de que "los niños y adolescentes son incapaces de formar y perseguir concepciones de ellos mismos y de sus bienes" (1996: 9). Por ello, entiende que los defensores de la escuela libertaria están más cerca del ideal liberal que los que defienden la educación básica y general.

Como se desprende de lo anterior, Flathman rechaza la perspectiva de la educación cívica y democrática puesto que profundiza en los aspectos iliberales que toda educación necesariamente tiene. Los fines de la educación cívica y democrática son, a su entender, impositivos y adoctrinadores. De hecho, discute la exigencia de que la ciudadanía ha de ser participativa. Antes al contrario, cuanto más hacemos nuestros los ideales de compromiso cívico y democrático, más incrementamos la fuerza del poder y del Estado. La penetración de la política en todos los ámbitos de la vida uniformiza a los individuos y resulta un ideal opresivo que podrá conseguir 
RIS

REVISTA INTERNACIONAL DE SOCIOLOCIA

№ 34, Enero-Abril, 2003

CARLOS MOUGÁN RIVERO

un estado próspero y apacible, pero de seres humanos serviles. La defensa de la concepción cívica y democrática reviste de un lenguaje de legitimidad y obligación lo que, en realidad, es obediencia a una élite. Frente a este ideal impositivo Flathman reclama la necesidad de mantener el pathos de la distancia. "Bajo la autoridad y el poder de educadores cívicos, republicanos y demócratas que han moralizado los ideales con nociones de bien, derecho, y obligación, el panorama de los "enemigos" del régimen es poco brillante" (1996: 22).

Flathman señala, acertadamente a nuestro entender, que su posición prolonga la perspectiva que en su día sostuvo J.S. Mill, para el que la educación debe contribuir al conocimiento general de los hechos de la vida, puesto que nos familiariza con cómo es y cómo ha llegado a ser el mundo, y permite que cada uno se oriente según sus propias disposiciones. Pero, y en esto se distancia de Mill, se trata de una reactualización que ha perdido de vista la convergencia en una moral de corte universalista pues, más que heredero de los supuestos ilustrados, Flathman reconoce la impronta nietzscheana en su argumentación.

La cercanía de este discurso con las posiciones románticas ${ }^{4}$ y libertarias desemboca, en el ámbito de la educación, en la crítica a todo intento de intervención y control por parte de los poderes públicos en materia escolar. Desde posiciones como las de Neill e Illich se comparte el ideal propio de la tradición liberal para la que uno sólo debe obedecerse a sí mismo y conseguirlo exige liberarse de influencias externas que obstaculizan el desarrollo de la autonomía individual. Neill e Illich, como los antiautoritarios radicales, no sólo quieren que se deje espacio para la libertad a los niños, no sólo quieren liberar al niño en la escuela, quieren liberarlo de la escuela.

En todo caso, para nuestro propósito, es necesario subrayar que el docente queda, bajo esta interpretación, al servicio de la construcción de la subjetividad individual autocreadora. Su único compromiso moral es con datos y hechos que están al servicio de fines educativos que le son marcados desde fuera.

b) El refugio en el mercado: el predominio de la perspectiva vocacional. La defensa de esta perspectiva parte de considerar la primacía de lo económico sobre lo político o cultural Se trata de una línea de pensamiento que arraiga en la tradición del liberalismo económico y que rechaza, hasta donde sea posible, la intervención del Estado, en nuestro caso también en la esfera de la escuela. El neoliberalismo, por utilizar la expresión en uso para hacer referencia al renacer de esta perspectiva, denuncia lo público como ineficiente e ingobernable. La

\footnotetext{
${ }^{4}$ Conviene en este punto recordar las ideas de Von Humboldt en Los límites de la acción del Estado donde señala: "Para mí el supremo ideal en la coexistencia de los seres humanos sería aquel en que cada uno se desarrollase solamente desde sí mismo y en virtud de sí mismo" (1998: 18).
} 
tesis, que ya hiciera suya Friedman (1980), de que los males que aquejan a las institucionales públicas derivan de la falta de competitividad que es producto de la intervención de los poderes públicos, y la consiguiente propuesta de abandonar dicho espacio a la lógica del mercado, ha adquirido nueva fuerza como consecuencia del crepúsculo de las ideologías que la crisis del paradigma moderno ha supuesto.

De la traducción de dicha perspectiva a la educación se sigue que la crisis de calidad de la institución escolar se debe a la fuerte presencia del Estado y de los poderes públicos en éste ámbito. No hay competencia, no funciona el principio castigo y recompensa y, como consecuencia, se convierte en un sistema donde no vale decir que los mejores triunfan y los peores fracasan. La receta neoliberal es el traspaso de la educación a la esfera de la competencia privada. La educación es una mercancía que debe funcionar bajo las leyes del mercado que optimiza los recursos y se adecua a las necesidades sociales.

No es nuestra tarea aquí discutir las virtudes y deficiencias de este esquema interpretativo, que nos llevaría lejos de las pretensiones del presente trabajo, pero sí señalar las implicaciones que de la misma se sigue para pensar el perfil moral de la tarea docente. De entrada resulta, por paradójico que pueda parecer, que este liberalismo económico implica el rechazo de la idea o concepto de "educación liberal" puesto que supone hacer prevalecer lo que podríamos denominar como perspectiva profesional o vocacional. Así, puesto que se entiende que la educación es una mercancía, entonces no se debe pensar en los padres y sus hijos como ciudadanos sino como clientes y consumidores, individuos que eligen y compiten por adquirir una mercancía determinada. Se entiende aquí que la escuela y la educación son un servicio que depende del usuario o cliente y que, por tanto, se debe a sus intereses y necesidades, y estos, a su vez, quedan definidos en función de la búsqueda inmediata de un puesto de trabajo. Así, para algunos, los contenidos de la enseñanza de la educación primaria prepara para los de la secundaria, éstos para los de la enseñanza profesional o la Universidad y estos, a su vez, para satisfacer las necesidades del mundo del trabajo. A juicio de Postman (1999), se trata de una nueva narrativa que trata de dotar de sentido a la escuela, "el dios de la utilidad económica" teniendo en la eficacia, en el análisis de la contribución de la escuela a la mejora de la productividad, el criterio de determinación de lo válido. A ello subyace el mensaje para el alumno: "si prestas atención en la escuela, haces tus deberes, sacas buenas notas y te portas bien, serás recompensado con un trabajo bien pagado cuando termines" (1999: 40). De esta forma la presión para capacitar a los alumnos con las capacidades y valores necesarios para que se adapten al mercado es tan fuerte que hace perder de vista las finalidades no instrumentales de la educación, aquellas que, como decíamos, habían justamente caracterizado a la enseñanza liberal. Así lo ha denunciado recientemente también Jurjo Torres en un libro dedicado expresamente a la relación entre neoliberalismo y educación. "La tan nombrada mundialización de los mercados pretende imponer como 
RIS

REVISTA INTERNACIONAL DE SOCIOLOCIA

№ 34, Enero-Abril, 2003

motor de la vida una racionalidad económica que se condensa en valorar todas las cosas sólo en la medida en que producen beneficios económicos, no sociales, ni morales. Ello explica que la educación pública y, lo que es más importante, su conceptualización de servicio público, pase a un segundo plano. La educación, incluso en sus etapas obligatorias, parece querer asumir, más cada día, como planteamientos los de la capacitación profesional; es decir, habilitar sólo para encontrar empleos y, a ser posible, bien pagados" (Torres, 2001: 31).

Lo que se pierde en esta perspectiva es la idea de que la educación pueda contribuir a algo más que la utilidad productiva y mercantil. Se trata de una reacción postmoderna porque niega lo que ha sido un rasgo esencial del relato moderno acerca de la educación: su sentido emancipatorio. En realidad no reacciona buscando una nueva filosofía de la educación, una nueva perspectiva que le de sentido, sino que niega todo sentido transformador y moral a la misma. Como señala Gimeno Sacristán, "la analogía del mercado en la educación verá a los estudiantes como consumidores, a sus padres como responsables de la elección del consumo, a los centros y a los profesores como proveedores de servicios y a los curricula como ofertas a elegir, lo que supone una interpretación forzada y empobrecedora del fenómeno educativo" (Gimeno Sacristán, 1998: 143).

En esta misma dirección el propio Gimeno Sacristán señala las consecuencias que se derivan de esta visión restrictiva de la educación para la tarea docente al señalar que el aumento de la libertad y autonomía de los padres supone rechazar la de los profesores: "La escuela sometida al mercado sólo es autónoma dentro de los márgenes de los gustos de los consumidores" (Ibidem, pg. 152). El docente ha de limitarse, desde esta interpretación, a desarrollar su papel sin que se considere que es de su competencia examinar las finalidades a las que la educación sirve. Es decir, se trata de una perspectiva que permite al profesor pensar sobre su tarea desde un perfil estrictamente técnico, como la de un profesional liberal que aparca su ideología y sus creencias cuando acude al trabajo porque entiende que éstas pertenecen al ámbito privado e inviolable de su conciencia personal. De nuevo aquí su tarea se pone al servicio de valores que le son marcados desde fuera.

Se puede matizar esta posición si las contrastamos con las expuestas anteriormente. Por un lado, y como ya se ha apuntado, se ha perdido en esta interpretación la perspectiva liberal ilustrada porque el neoliberalismo, a diferencia del anterior, ya no se ocupa de la defensa de la individualidad, su desarrollo y su autonomía frente al grupo social. Por el contrario, se dan por válidas las prácticas sociales vigentes. Por otro, se diferencia de los discursos antiautoritarios radicales. Estos tienen un propósito moral último, puesto que están guiados por el ideal de autorealización, mientras que en la perspectiva neoliberal se consagra el éxito social como el único criterio de valor de referencia. La extensión e importancia de esta visión de lo educativo se deja ver en el creciente número de análisis y estudios que tratan de poner en relación productividad y sistema educativo juzgando a aquél como el único parámetro de bondad de éste. 
c) El discurso de la diferencia: el minimalismo civico. Como señalamos en relación con el pluralismo de la razón, ésta se ha convertido en el eje alrededor del que se articula la renovación de la teoría política liberal. De hecho, el mayor empuje doctrinal que la tradición liberal ha recibido viene de la mano de Rawls y, más en concreto, de su obra Liberalismo Politico. Como él mismo indica, el punto principal que provoca el paso de la Teoría de la Justicia al Liberalismo Político radica en la necesidad de incorporar el pluralismo axiológico dentro de su teoría. Esto es, deseaba hacer compatible su teoría con las diversas concepciones completas del bien que inevitablemente se dan en el seno de una sociedad democrática. Lo que para Rawls es importante es que su concepción de la justicia sea públicamente justificable para los miembros de una sociedad que se caracteriza por el hecho del "pluralismo razonable". La diversidad de doctrinas religiosas y filosóficas, incompatibles, pero todas ellas razonables, no es una simple circunstancia histórica, sino el resultado normal del ejercicio de la razón en el marco de instituciones libres. El pluralismo es razonable porque no es meramente el producto o el resultado de intereses individuales o de clase, ni de fallos lógicos o de racionalidad. Descontando todo esto es imposible llegar a acuerdos respecto a cuestiones globales. Es a esto a lo que Rawls llama las cargas del juicio. Éstas son: la complejidad de las pruebas, la valoración de las mismas, la vaguedad de nuestros conceptos, y la necesaria influencia de nuestra experiencia. Cuando los seres humanos ejercen la razón en el marco de unas instituciones libres, el desacuerdo es inevitable, pero razonable.

El modelo de Estado liberal para Rawls emerge de las guerras de religión inglesa de los siglos XVI y XVII y se habría constituido por neutralización política de las concepciones del bien, demasiado antagónicas para fundar un consenso que permita la coexistencia. El nacimiento y devenir del liberalismo político se habrían correspondido entonces con el proyecto de concebir el Estado como un Estado neutro con respecto a esas concepciones del bien.

El liberalismo político parte de considerar que sería bueno dejar de lado las verdades religiosas y los ideales de perfección humana e intentar justificar las cuestiones más básicas de la justicia sobre fundamentos ampliamente aceptables para la gente razonable. Por ello, el liberalismo político no depende de tomar una posición acerca de la vida buena, no es un liberalismo comprehensivo, y, consecuentemente, no puede estar sesgado a favor de determinadas doctrinas comprehensivas, como por ejemplo, una vida comprometida con los valores de autonomía e individualidad. Que la buena vida consista en la autonomía puede ser considerado como un punto de vista tan sectario como cualquier otro y, desde luego, no más valioso que los demás para ser promovido por la autoridad pública. En el ámbito de lo educativo, y en relación con los grupos que se oponen a la cultura del mundo moderno, Rawls deja claro que no se puede sostener una absoluta neutralidad, puesto que el liberalismo que él defiende exige que "la educación de los hijos incluyera cosas tales como el conocimiento de los derechos constitucionales 
y civiles, de modo que, por ejemplo, llegaran a saber que existe en su sociedad la libertad de conciencia, y que la apostasía no es un crimen legalmente perseguible" (Rawls, 1996: 234). La enseñanza de derechos cívicos y constitucionales naturalmente pone límites a la diversidad, pero son límites que es necesario defender justamente en nombre de los derechos y oportunidades de los otros. Rawls acepta, aunque lamentándolo, que dicha promoción de la conciencia cívica suponga un determinado sesgo a favor del liberalismo comprehensivo, pero se trata de un mínimo inevitable que no rompe el núcleo de su concepción política. De ahí que insista en que "además de las exigencias ya descritas, la justicia como equidad no pretendía cultivar las distintas virtudes y valores liberales de la autonomía y la individualidad: tampoco los de cualquier otra doctrina comprehensiva" (Ibidem, 234).

Es una posición muy cercana a la de los autores individualistas y antiautoritarios que caracterizamos antes, pero se diferencia, no obstante, de la de ellos. Así, en relación con el caso de Flathman (1996), éste considera que la defensa del pluralismo y de la diversidad de los minimalistas es deficiente porque, a su juicio, está más preocupada de los límites del mismo que de las dificultades que pueda tener. Su tesis es que el liberalismo político de Rawls, y la defensa del mismo que hace Macedo, con quien él polemiza, no estimula de manera suficiente la diferencia. Para Flathman, el principal argumento a su favor es que, dado que la diversidad es un hecho, un dato, el pluralismo es una ideología que no sólo tolera sino que da la bienvenida a la variedad y la diferencia porque es esencial para la felicidad de los miembros de una sociedad. Así, en su réplica a Macedo apunta que:

"Puesto que sus vidas consisten en sus valores y creencias y en perseguir sus propios objetivos y propósitos, en la medida en que la sociedad los desanima o los previene de pensar y actuar como ellos consideran adecuado les hace vivir sus vidas de manera desgraciada. La misma ideología del pluralismo es errónea y debe ser transformada hacia una orientación en la que triunfa una forma de diversidad mucho más radical que la de los grupos o asociaciones, que es la individualidad auto - creadora" (Flathman, 1998: 82)

Esto es para Flathman, como para Galston ${ }^{5}$, la pluralidad favorece la vida buena, no es un dato sin más de la vida social. A su juicio, Macedo, como el liberalismo político, encarna un "liberalismo orientado hacia la virtud" frente al que Flathman se sitúa por considerar que colaboran con la tendencia a producir conformidad y

\footnotetext{
${ }^{5}$ W. Galston (1991), a diferencia del liberalismo político de Rawls, habría venido a defender en Liberal Purposes que el liberalismo implica la defensa de un conjunto de virtudes. Ahora bien, estas virtudes no están asociadas con el valor de la autonomía, sino con el de la pluralidad. He desarrollado una comparación entre las posiciones educativas del liberalismo político de Macedo y el de Galston, en Mougán (2000).
} 
homogeneidad, a reprimir la iniciativa y a inutilizar la creatividad. La respuesta de Macedo no puede ser más significativa para nuestro propósito, pues reconoce que ambos se encuentran en posiciones cercanas, pero matiza, frente a Flathman, que lo que no pueden evitar es que su propia defensa de una concepción política esconda una serie de virtudes sin las que la individualidad no puede crecer. Así, autocontrol, moderación, respeto a las formas, etc.. Esto implica una cierta restricción acerca de los modos de vida bueno que le alejan de la neutralidad. La dificultad de mantener que se trata de un punto de vista estrictamente político y, al mismo tiempo, defender la promoción de virtudes consistentes con el pluralismo es manifiesta y se hace patente en el propio texto de Rawls:

"La preocupación de la sociedad por su educación tiene que ver con su papel como futuros ciudadanos, y así, con cosas esenciales tales como la adquisición de una capacidad para entender la cultura pública y participar en sus instituciones, con su capacidad para conseguir independencia económica y convertirse en miembros autosuficientes de la sociedad a lo largo de un ciclo vital completo, así como con su adquisición y desarrollo de las virtudes políticas. Y todo ello sin abandonar un punto de vista político" (Rawls, 1996: 235).

En todo caso, desde esta perspectiva teórica, y a diferencia del libertarismo antiautoritario, se rechaza describir al docente como una figura neutral moralmente, pero se entiende que su compromiso moral es el mínimo posible, el que partiendo de los mínimos marcados constitucionalmente garantiza, justamente, la coexistencia de la mayor pluralidad posible. De ahí que pueda caracterizarse como minimalismo cívico.

\section{ARGUMENTOS PARA RECONSIDERAR EL MINIMALISMO MORAL DOCENTE}

El minimalismo moral supone la revitalización de algunos aspectos del liberalismo moderno, pero sin los presupuestos antropológicos y morales que caracterizaban a éste. Pues bien, de la misma manera que el desarrollo y la crisis del concepto de educación liberal ha ido de la mano de la evolución y declive de la tradición política liberal ilustrada, el establecimiento de posiciones alternativas al minimalismo moral ha de nutrirse de las tradiciones de pensamiento críticas con el liberalismo. Así, en el marco de las últimas décadas, se ha desarrollado en el ámbito de la teoría política otros modelos de interpretación de los valores éticos y políticos que, bajo los rótulos de comunitarismo y republicanismo, pueden servir de punto de referencia para analizar y valorar la ética de la profesión docente. No se trata aquí de analizar las virtudes y defectos de éstas corrientes de pensamiento, sino tan sólo de utilizar algunas de sus argumentaciones para 
RIS

REVISTA INTERNACIONAL DE SOCIOLOCIA

№ 34, Enero-Abril, 2003

CARLOS MOUGÁN RIVERO

desarrollar una lectura más adecuada de la ética de la profesión docente dentro del marco de la sociedad en la que nos movemos, y mostrar las insuficiencias de las posiciones caracterizadas en el apartado anterior. Los argumentos que exigen reconsiderar el minimalismo moral que se desprende de las posiciones liberales postmodernas son los siguientes.

\section{A) La democracia requiere virtudes cívicas}

La democracia, concebida en su sentido político como un sistema de gobierno, supone un ordenamiento jurídico y una estructura institucional (sistema de representación, sufragio universal, partidos políticos, derechos individuales, etc.). Pero, además, la democracia se asienta sobre la afirmación de un conjunto de valores sin los cuales ve amenazada su existencia y propagación. Así, en un reproche a lo que ha sido la tradición antiperfeccionista de la tradición liberal, Berkowitz ha manifestado que "la operación y mantenimiento de la democracia liberal dependen del ejercicio de virtudes morales e intelectuales, que según la versión canónica del liberalismo caen fuera de su propia supervisión, y que no sólo se abstiene de invocar sino que incluso desalienta o socava" (Berkowitz, 2001: 26). En este sentido se ha afirmado, desde diversos ángulos, que los peligros para la democracia en la actualidad no derivan tanto de la existencia de regímenes alternativos sino de la extensión de convicciones, creencias, y valores contrarios a los de la democracia. La apatía, el desinterés por lo público, la falta de aceptación de las diferencias, el rechazo a participar en las cuestiones públicas, la ausencia de diálogo y de prácticas reflexivas se convierten en obstáculos de gran importancia para el avance y la profundización en la democracia.

La educación tiene que jugar en esta dirección un papel que siempre le ha correspondido, al menos parcialmente, esto es, el papel conservador de sostener y fortalecer los mecanismos e instituciones sociales. De esta forma, la educación debe actuar como un agente socializador en el sentido que ya Arendt señalara: el de contribuir al mantenimiento de lo mejor de nuestra tradición (Arendt, 1996). Una primera fuente de legitimación de la promoción de determinados valores, prácticas y virtudes proviene de la necesidad del propio sistema social de subsistir. Hace falta, desde esta óptica, una educación que fomente y extienda prácticas ciudadanas adecuadas, acordes con el espíritu, los valores y las creencias de la democracia.

Esto supone un rechazo de las posiciones minimalistas, vistas en el apartado anterior, que coinciden en pensar la tarea docente, desde una perspectiva liberal, de un ejercicio profesional que puede ser deslindado de implicaciones de carácter valorativo, ético o político. A dichas concepciones, pese a sus diferencias, subyace una manera común de entender la democracia y la política. Se sobreentiende en ellas que la participación y los deberes para con nuestra comunidad son un asunto individual que pertenece al ámbito de la elección moral personal, que no es importante que los ciudadanos tengan una preparación especial para la vida 


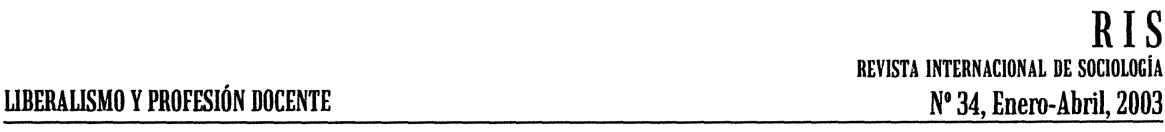

política, que la democracia es un sistema de organización política e institucional que se mantiene por su propia dinámica, o que basta para ello con un cuerpo de profesionales dedicados a tal efecto. En lo que respecta a los objetivos de nuestro trabajo la cuestión es, sobre todo, que no consideran importante que los ciudadanos piensen, reflexionen y debatan en público acerca de cuestiones que afectan a la marcha de los asuntos colectivos, y que no hay nada anómalo en el desinterés por la suerte de los demás.

\section{B) El fracaso de los agentes socializadores}

Como se desprende de la anterior cita de Berkowitz, y frente a una cierta imagen que se ha hecho canónica en relación con el liberalismo, no es cierto que históricamente los liberales hayan desestimado como innecesario o inadecuado la promoción de un conjunto de valores para el sostenimiento de las sociedades liberales. Antes bien, existían una serie de "fuentes extraliberales o extraoficiales donde el liberalismo abrevaba en el pasado para alentar las virtudes necesarias para su mantenimiento - sobre todo la familia, la religión y las asociaciones de la sociedad civil-" (Berkowitz, 2001: 27). El problema es que estos agentes socializadores han perdido en eficacia, en cuanto a la fuerza con la que transmitían valores, $\mathrm{y}$ en homogeneidad, en cuanto a sus contenidos. Esta pérdida de capacidad para transmitir eficazmente valores y pautas culturales de cohesión social viene a constituir uno de los rasgos característicos de nuestra época. En palabras de Tedesco se trata de un "deficit de socialización" que no ha sido cubierto por los nuevos agentes de socialización, en especial la televisión, puesto que no han sido diseñadas como entidades encargadas de la formación moral y cultural de las personas.

Por otro lado, la transformación en el proceso de socialización hace que se rompa uno de los pilares en los que estaba basada la educación formal: el supuesto por el que el núcleo básico de la socialización ya está dado por la familia. Las modificaciones en el proceso de socialización hacen que se produzca "una disociación entre escuela y familia a través de la cual los niños llegan a la escuela con un núcleo básico de desarrollo de la personalidad caracterizado bien por la debilidad de los marcos de referencia, bien por marcos de referencia que difieren de los que la escuela supone y para los cuales la escuela se ha preparado" (Tedesco, 1995: 44).

Podemos simplificar diciendo que cuando la familia socializaba, la escuela podía ocuparse de enseñar. Puesto que la familia no cumple su papel socializador, la escuela no puede cumplir eficazmente su papel y comienza a ser objeto de nuevas demandas para las cuales no está preparada. Por ello, y frente a las pretensiones de las posiciones neoliberales que defienden una escuela que se bate en retirada en el ámbito de la moralidad, el análisis de los rasgos del proceso de socialización en el marco de nuestra sociedad parece indicar el camino contrario, 
RIS

REVISTA INTERNACIONAL DE SOCIOLOCIA

№ 34, Enero-Abril, 2003

CARLOS MOUGÁN RIVERO

el de la necesidad de un rearme en valores que afecta, de lleno, a una nueva manera de pensar el papel del docente en nuestra sociedad.

\section{C) Principios liberales, vicios sociales}

Por otro lado, las tradiciones de pensamiento críticas con el liberalismo han querido poner de manifiesto que uno de los defectos de la tradición liberal, y de nuestra sociedad, es la primacía del individuo, el exceso de individualismo. De esta forma parece echarse de menos en la tradición liberal la conexión entre el desarrollo y perfeccionamiento del yo, y la sociedad o comunidad que conforma a ese individuo. En este sentido parece oportuno, y más teniendo en el horizonte las cuestiones educativas, considerar si las instituciones sociales propias de una sociedad liberal generan por su misma dinámica individuos acordes con los principios en los que se basan esas mismas instituciones. Berkowitz, al analizar dicha relación concluye: "los principios liberales parecen generar vicios característicos, vicios que están entrelazados con las virtudes liberales y amenazan la capacidad de los ciudadanos para sostener instituciones libres y democráticas" (Berkowitz, 2001: 27)

Lo que se pone en cuestión es el supuesto liberal de que bastará con la ausencia de obstáculos externos para que la libertad y la autonomía estén garantizadas. El error radica en asumir que los individuos tienden natural y espontáneamente hacia el ejercicio de la razón y de la libertad olvidando, por tanto, que en cuestiones de índole moral, aunque quizá no sólo en ella, la doctrina del laissez faire no tiene por qué producir buenos resultados. El error es asumir que "las condiciones que permiten el ejercicio de la autonomía son las condiciones para el desarrollo de la autonomía" (Thiessen, 1993: 142). Si bien es verdad que la libertad de expresión y la ausencia de restricciones son condiciones del librepensamiento, es necesario también subrayar que no bastan esas condiciones para que el ejercicio del pensamiento libre fluya. También Galston se hace eco de esta idea pues, tras indicar como factible lo que denomina hipótesis pesimista por la cual "las poderosas corrientes de la cultura contemporánea liberal tienden a socavar las virtudes liberales", señala que la tarea de renovar y fortalecer las virtudes liberales requiere, más que mejorar las instituciones formales de la educación cívica y moral, "un esfuerzo sostenido para revertir las tendencias corrosivas fundamentales para la cultura moderna" (Galston, 1991: 233). Dicho de otro modo, los principios liberales en el ámbito social no son ninguna garantía de consecución de excelencia moral, lo que supone, en el ámbito educativo, el rechazo de las posiciones minimalistas expuestas en al anterior apartado.

\section{D) La construcción social del conocimiento}

La definición de la tarea docente desde una perspectiva exclusivamente técnica 
está basada en una imagen positivista del conocimiento que parece hoy obsoleta. Una consideración más precisa de la evolución del conocimiento y la investigación pone de manifiesto que ésta es dependiente de la comunidad científica. Que nuestro razonamiento depende de la comunidad en la que estamos insertos y que la validez de nuestros asertos depende de la estructura de esta comunidad es algo que es necesario tener en cuenta no para desvalorizar la empresa científica sino para poner de relieve la importancia de factores extracognitivos en la formulación del saber y en la propagación del conocimiento. Así, Thiessen ha señalado que "el énfasis en la reflexión crítica independiente está típicamente asociada con el concepto de educación liberal pero debe ser equilibrado con una consideración acerca de los límites inherentes a la naturaleza humana que subrayan la importancia de la tradición y la autoridad" (Thiessen, 1993: 107).

$\mathrm{La}$ imagen que en educación se transmite a menudo de la ciencia, como un tipo de empresa relacionada con la prosecución de verdades objetivas e intemporales y la demostración irrefutable de pruebas, es una imagen ya caduca del conocimiento. Necesitamos poner de manifiesto las bases sociales, políticas y morales sobre las que se asienta la tarea científica como una tarea educativa de primer orden. No puede olvidarse, en este sentido, que la ciencia es un propósito decididamente humano y social y no se le debe exigir otra lógica que la propia a los seres humanos. Se trata de entender la racionalidad como un proceso continuado de justificación de creencias por parte de individuos que tienen una determinada psicología, una historia y que forman parte de una sociedad con tradiciones.

Si estamos de acuerdo en que la racionalidad, su crecimiento y desarrollo es dependiente del contexto social, de los valores sociales establecidos, de las fuentes de autoridad que, se quiera o no, sirven de referencia a los humanos, entonces hemos de concluir que el desarrollo de la racionalidad sólo se puede producir si se proporciona el contexto valorativo adecuado. Por tanto, hablar de crecimiento moral del individuo, en tanto que relacionado con el conocimiento, requiere la afirmación de un conjunto de valores que nutren nuestra interpretación del significado de la racionalidad humana. La idea de un concepto de razón considerado como un factor unidireccional que conduce hacia el bien ha quedado descartado. Por ello, cabe hablar no tanto de razón en abstracto cuanto de formas de racionalidad. La educación debe velar para desarrollar aquéllas que sean compatibles y coherentes con nuestra manera de entender la democracia. En este sentido, el siglo XX nos habría mostrado que determinados desarrollos de la razón, que han prescindido de elementos valorativos, han producido grandes monstruosidades. De otro modo, el cultivo de las habilidades lógicas, de la capacidad computacional o científica, en el sentido más estrecho de la palabra, no garantiza un avance desde el punto de vista moral, y la razón, en un significado que se precie, ha de estar comprometida con la promoción de determinadas formas de vida buena.

Desde luego, no se trata de rechazar que el conocimiento y el entendimiento no sean valores, sino de tener cuidado en no asumir que de por sí conducirán 
RIS

REVISTA INTERNACIONAL DE SOCIOLOCIA

№ 34, Enero-Abril, 2003

CARLOS MOUGÁN RIVERO

a la virtud moral y a la salvación de la sociedad, como parecían sostener los defensores de la tradición liberal. Más bien, se trata de reinterpretar el valor del conocimiento dejando de lado el punto de vista de la adquisición de la verdad y relacionándolo con los valores y virtudes asociados con la educación liberal: coherencia, consistencia, imparcialidad, tolerancia, claridad, atención a la evidencia, respeto por las personas como fuentes de puntos de vista que pueden ser correctos, y humildad y reconocimiento de que se puede estar equivocado. $\mathrm{La}$ cuestión no es rechazar la racionalidad, sino reafirmarla a luz de los valores que la hacen hoy estimable.

Así, lo que se está rechazando aquí es la figura de lo que podríamos denominar, por analogía con expresión de Del Aguila, el "profesor impecable" (Del Aguila, 2000). Es éste el que considera que su tarea está libre de cualquier compromiso político, que su trabajo es con el conocimiento, con el ascenso a la verdad y el bien y que, consecuentemente, está en su profesión libre de la política, más allá de ella. Como en el modelo liberal clásico cree que basta con el compromiso con el conocimiento, aunque sus ideas ya no están fundamentadas en la cosmovisión ilustrada y carecen de un proyecto moral, de una visión emancipatoria de nuestra sociedad. El "profesor impecable" piensa que es posible hacer un perfil de su tarea sin vincularlo con opciones ideológicas y políticas determinadas. Incluso en el caso de que entienda que la educación es ideológica, estima que la definición de la misma no es su tarea, que su papel como profesional se ajusta a la defensa de la verdad y del conocimiento.

\section{E) Hacia una nueva defensa del valor del individuo}

Todo lo anterior no puede ser interpretado como un rechazo total del punto de vista liberal. La educación ha de ser hoy en día liberal, en el sentido de que el primer objetivo de toda educación democrática ha de ser el fomento y desarrollo de la individualidad ${ }^{6}$, y esto significa hacer del individuo un ser autónomo en el sentido que autores como Kant o Mill defendieron. Ahora bien, la idea de autonomía interpretada en términos absolutos es claramente deficiente pues falla en reconocer que el individuo elige y toma decisiones siempre en un contexto y que está condicionado por su herencia. La autonomía, como la capacidad de reflexión crítica, siempre se ejerce sobre el trasfondo de una comunidad de convicciones. Naturalmente es propio de la racionalidad y la reflexión la capacidad de ir más allá de lo establecido socialmente, pero esto sólo sucede dentro de unos límites, pues sólo se puede ejercer la razón desde una orientación previa. Como se mostró en el punto anterior, el ejercicio de la razón requiere de un subsuelo de valores que lo hace posible. Si es cierto que nuestra identidad y nuestro pensamiento se

\footnotetext{
${ }^{6}$ Estas ideas han sido ya desarrolladas en Carlos Mougán (2000).
} 
conforma, en parte, en función del medio exterior donde se realiza, entonces un pensamiento autónomo exige un medio social donde exista confianza y aceptación de las diferencias, capacidad para adoptar puntos de vista diferentes y alternativos, reglas de comportamiento estables en un ambiente normativamente predecible, etc.. Por el contrario, el exceso de permisividad o su ausencia, la falta de un medio coherente, el autoritarismo, el egocentrismo, el desinterés por lo colectivo, la ideología del éxito fácil, son condiciones que impiden el desarrollo del pensamiento en general y de la autonomía moral en particular.

Así pues, individuo y libertad son el resultado de un proyecto político, histórico y cultural. Y si la nuestra es aquella civilización que ha optado por hacer de la libertad el eje de su organización social y política entonces habrá que reconocer la necesidad de forjar individuos liberales en el seno de nuestra sociedad, máxime si es cierto, como apuntamos anteriormente, que las instituciones liberales tienden a producir vicios antiliberales. El liberalismo surgió como defensa de la individualidad frente a un orden social que ahogaba la libre iniciativa, que no permitía el libre crecimiento de la individualidad. Se trató de conquistar un espacio para el individuo frente al Estado. De ahí que, en nombre de la defensa de la libertad individual, se proclamó la necesidad del abstencionismo, de la neutralidad o de la mínima intervención por parte del Estado. Esta perspectiva, que pudo ser legítima en unas condiciones sociales determinadas, ha cambiado hoy significativamente, de forma que el desarrollo de la individualidad está siendo, hoy, sometido a nuevas y diferentes trabas. La lucha por los derechos individuales contra el Estado debe hoy extenderse a la defensa de la individualidad contra las fuerzas sociales y económicas que, constituyéndose en nuevos agentes de socialización (televisión, medios de comunicación, etc.), introducen una nueva forma de adoctrinamiento moral. Los valores relacionados con la austeridad, la sobriedad, el compromiso con los demás, el sentido del esfuerzo y del sacrificio, la conciencia de que los bienes son escasos y que no es legítimo utilizar las creencias de la índole que sean para marginar, humillar o simplemente separarnos de los demás, son valores que han de ser promovidos en nombre del desarrollo de la individualidad que el propio liberalismo proponía. Lo contrario es abandonar al individuo no a una esfera de libre decisión interna, a la autonomía, sino dejarlo a expensas del "adoctrinamiento" moral que el propio mecanismo de mercado impone. $Y$ eso no es más libertad, más autonomía, ni más pluralidad, sino menos. La capacidad de distanciarse críticamente del entorno, de adoptar normas y pautas de conducta críticos con el medio en el que vivimos es el santo y seña del liberalismo, y ha de ser defendido por la escuela.

Desde la perspectiva que estamos defendiendo, fomento de la individualidad y potenciación de la democracia a través de la deliberación son direcciones enteramente convergentes (Dewey, 1927). Probablemente podemos decir que la democracia necesita de más individualidades $\mathrm{y}$, al mismo tiempo, sostener que el nuevo individualismo lo que requiere es de la extensión de los valores demo- 
cráticos. De este modo, sostener que el docente debe estar al servicio de la construcción del sujeto no puede significar que ha de plegarse a sus deseos, intereses o necesidades, sino que ha de subordinar éstos a la consecución de un tipo de individuo acorde con el modelo de sociedad democrático. Por ello, la educación liberal se debería entonces caracterizar como aquella que amplía los horizontes del individuo. Educar liberalmente es enseñar a considerar los problemas desde distintos ángulos, alejándose de una consideración trivial, superficial o unilateral de las cosas. El compromiso ético del profesor liberal es el de mostrar las cosas de manera que se aprecie la complejidad de las cuestiones, considerando posiciones diversas, discutiendo perspectivas alternativas. Es verdad que la educación liberal es la que permite a las personas ir más allá del presente y de lo particular, pero el reconocimiento de ello debe ir vinculado al compromiso con un conjunto de valores que hacen plausible el distanciamiento con lo establecido socialmente.

Desde esta perspectiva, debemos replantear la oposición entre adoctrinamiento y autonomía. Como ya señaló Dewey, la cuestión en educación no es si imponer o no, sino la naturaleza de lo que se impone. Por ello el adoctrinamiento cabe redefinirlo como el fracaso en no hacer ver a los estudiantes los argumentos en los que se apoya. Puesto que la transmisión de valores es un dato ineliminable de la realidad educativa, decimos que hay adoctrinamiento cuando hay ausencia de conciencia y reflexividad.

\section{ÉTICA DEL DOCENTE BAJO EL CONCEPTO DE "EDUCACIÓN PARA UNA CIUDADANÍA DEMOCRÁTICA"}

\section{a) Notas para la elaboración del concepto de "educación para una ciudadanía democrática".}

Si se acepta que nuestro régimen político, esto es, la democracia, es un orden político que contiene exigencias morales, y que la educación debe contribuir al mantenimiento de nuestro sistema político y a la promoción de los valores, hábitos y virtudes que permiten su fortalecimiento y profundización entonces debemos caracterizar el concepto de "educación para una ciudadanía democrática" como el marco teórico desde el que reinterpretar la ética de la profesión docente bajo un nuevo prisma. Partiendo de los argumentos empleados en el apartado anterior podemos sintetizar los rasgos de esta concepción alternativa al minimalismo moral en los siguientes puntos:

1. Si la educación ha de contribuir a formar ciudadanos es importante comenzar por subrayar que ser ciudadano no es una condición natural del ser humano sino resultado de un proceso histórico y cultural mediante el que se ha normativizado el carácter ineludiblemente social del ser humano. La importancia educativa de este rasgo de la ciudadanía es máxima por cuanto que si es construido cultural- 
mente, entonces hay que reconocer que también ha de ser mantenido de la misma manera, y que la educación debe jugar en ello un papel importante.

Ahora bien, por otro lado, el concepto de ciudadanía en el seno de la sociedad democrática exige incorporar las dos tradiciones de pensamiento desde las cuales se ha venido defendiendo dicho concepto. De un lado, y desde el seno de la tradición liberal, se habría venido abriendo paso una defensa jurídica del concepto de ciudadanía por la que ser ciudadano significa haber adquirido un conjunto de derechos que, regulados positivamente, le reconocen a uno como miembro de la comunidad política. Pero, además de esta perspectiva individualista, hay otra tradición que se remonta a Grecia y que habría venido insistiendo en que ser ciudadano no supone sólo tener derechos sino que implica también deberes y obligaciones, que entiende que ser ciudadano es participar en la sociedad.

Bajo nuestro punto de vista, la consideración del concepto de ciudadanía en el seno de una sociedad democrática debe incluir tanto ésta última perspectiva, más republicana, como aquélla que reconoce derechos inalienables del individuo. Educar para una ciudadanía democrática ha de suponer, por tanto, educar al individuo para que reconozca los derechos que como cualquier ciudadano tiene, y para que sepa utilizar los mecanismos que permiten el ejercicio de los mismos, pero también educar en los principios, prácticas y convicciones que le habiliten para vivir de acuerdo con las exigencias y deberes sociales que impone una sociedad democrática.

2. Puesto que la democracia alude a la idea de que una colectividad puede autogobernarse, la educación democrática ha de significar educación en el autogobierno. Las organizaciones dedicadas a promover la educación cívica y democrática lo han apuntado así, queriendo indicar que es necesario desarrollar la perspectiva de origen aristotélico de que los miembros de una comunidad políticas son sus ciudadanos si participan en ella ${ }^{7}$. Ahora bien, la participación no es un desideratum en sí mismo, sino que debe ser una participación informada, basada en la reflexión crítica, en la comprensión de los derechos y responsabilidades. La educación aparece como un factor esencial de la ciudadanía en un régimen democrático, puesto que pone las condiciones necesarias para el ejercicio activo y responsable de su papel como miembro de la polis. Lo distintivo de la democracia es que son los ciudadanos los que deciden su futuro y, por ello, es necesario cultivar las capacidades que hacen posible que un colectivo determine su propio destino. La escuela, en la medida en que puede reproducir algunas de las condiciones políticas a escala de comunidad reducida, aparece, además, como uno de los ámbitos privilegiados para la extensión de la conciencia democrática.

\footnotetext{
${ }^{7}$ Así por ejemplo la organización Civitas que agrupa a las asociaciones dedicadas a defender la educación para la democracia. A este respecto ver Bahmueller (página web www.civnet.org).
} 
RIS

REVISTA INTERNACIONAL DE SOCIOLOCIA

№ 34, Enero-Abril, 2003

CARLOS MOUGÁN RIVERO

Por otro lado, la ciudadanía democrática hace referencia no sólo a un elemento conservador de la sociedad, sino también a un componente normativo, puesto que incluye valores y normas que sirven de referencia para la transformación social. En este sentido, el concepto de ciudadanía arrastra tras sí una larga tradición emancipatoria que había entendido que la escuela es un agente privilegiado para la transformación social. El poner en primer plano la educación para la ciudadanía significa recuperar esta dimensión de crítica social que la escuela ha de tener ${ }^{8}$.

3. Por su parte, Gutmann señala que el ideal de la educación democrática es la "reproducción social consciente". Según Gutmann los ciudadanos democráticos han de apoyar una política educativa de la cual puede ser dicho lo siguiente: "son prácticas y autoridades a las que nosotros, actuando colectivamente como sociedad hemos conscientemente acordado. Esto significa que una sociedad que apoye la reproducción social consciente debe educar a todos los niños para que sean capaces de participar en la definición colectiva de la sociedad (Gutmann, 1987:39)".

$\mathrm{La}$ diferencia a este respecto entre una educación democrática y otra que no lo es no radica por tanto en que una transmita valores y la otra no, como quizá se pretende desde una perspectiva liberal en defensa del valor de la libertad, sino que la educación democrática hace explícito y somete a discusión y debate público aquellos valores que inspiran y propaga el sistema educativo. La escuela democrática no ha de caracterizarse por su asepsia o neutralidad, sino más bien por su compromiso con los valores que hacen posible la organización democrática. De otro modo, lo que se ha de promover son las virtudes y el carácter moral que da a los individuos la posibilidad de definir colectivamente la sociedad. Para los ciudadanos de una democracia liberal una buena vida y una buena sociedad requieren libertad de elección individual pero también colectiva.

4. Por otro lado, al poner en primer plano la educación cívica se quiere expresar el carácter primordialmente político de la educación. De acuerdo también en esto con Gutmann, es legítimo sostener que en una sociedad democrática la educación política, esto es, el cultivo de las virtudes, el conocimiento y las habilidades necesarias para la participación política tiene primacía moral sobre otros objetivos de la educación pública. Esta primacía de la educación política proporciona criterios para dirimir tanto los debates sobre aspectos generales como la intervención del estado en los colegios, la separación o agrupación de alumnos, la educación religiosa, etc., como para las cuestiones relativas a las finalidades y procedimientos educativos. Esto es, a la hora de analizar las prácticas de los estudiantes cabe plantearse no sólo hasta qué punto dichas prácticas mejoran los logros académicos del estudiante sino también en qué medida las mismas pueden descuidar las virtudes de la ciudadanía.

\footnotetext{
${ }^{8}$ Parece oprtuno destaca en este sentido el libro de Giroux (1993).
} 
Así, frente al discurso cientifista que ha considerado los objetivos de la educación desde una perspectiva exclusivamente psicologista, poniendo en primer plano el concepto de individuo y de sujeto, la educación para la ciudadanía acentúa la dimensión política de la educación. No formamos individuos que se construyen según unas pautas internas de desarrollo de acuerdo con leyes de la psicología, sino ciudadanos que han de comportarse de acuerdo con reglas que son decididas no por una ciencia sino por una comunidad política. En el ámbito de la educación en valores esto lleva ocurriendo desde hace algún tiempo cuando los únicos análisis pertinentes para la educación moral parecían ser lo que provenían de la psicología, y el único discurso posible el que hablaba de estadios psicológicos de desarrollo.

\section{b) Contenidos de la educación para una ciudadanía democrática.}

Los contenidos de la educación para una educación democrática han de incluir conocimientos, habilidades y actitudes o virtudes cívicas. En lo relativo al conocimiento han de ser aquéllos imprescindibles que permitan al ciudadano ser conscientes de la estructura y funcionamiento de la sociedad en la que vive. Incluye, por tanto, el conocimiento del entramado jurídico e institucional (sentido y misión de la constitución, división de poderes, derechos individuales,...), los principios que regulan su funcionamento (mecanismos del gobierno, actuación de los partidos políticos, ...) así como el sentido y la justificación racional de todo ello (naturaleza y sentido de las leyes, conflicto y desobediencia,...). Sería oportuno incluir, junto con lo anterior, cuestiones relativas a las realidades político institucionales de ámbito internacional.

En segundo lugar, la educación cívico democrática debe desarrollar las destrezas y habilidades intelectuales que permiten participar en los asuntos públicos. Son destrezas que han de habilitar al individuo con la capacidad de adoptar posiciones propias razonadas sobre la base de información pertinente y adecuada. Son habilidades también que han de facultar a los individuos para trabajar cooperativamente, negociar con otros y, en fin, todo lo que implica la contribución a un propósito colectivo.

Pero en relación con los objetivos del presente artículo, interesa más destacar las virtudes que la educación cívica y democrática debe contribuir a promover en el sobreentendido de que han de formar parte de la tarea docente. Sin ánimo de exhaustividad, sino tan sólo de apuntar algunas líneas de razonamiento, cabe señalar a este respecto lo siguiente.

De acuerdo con lo mencionado más arriba, tener en cuenta las exigencias morales que conlleva la democracia exige que no se puede entender la sociedad como un mero agregado de intereses individuales. Se rechaza pues la suposición de que no hay mejor resultado colectivo que el que es consecuencia de la persecución del interés individual. Algunos autores liberales, como vimos en el apartado 


\section{RIS}

tercero, lo habrían entendido así por lo que, desde el punto de vista educativo, bastaría en nuestras sociedades liberales con conseguir que los individuos sean estratégicamente capaces de promover su bien individual, que sean capaces de moverse bien en la sociedad, para que se hubiera maximizado su libertad individual. Por el contrario, bajo nuestro punto de vista el sistema educativo tiene el deber de promover en los alumnos la conciencia de que la maximización de los intereses individuales, entendidos de manera particularista (conseguir un buen puesto de trabajo, dinero, posición social, etc.) supone una perspectiva inmoral. Se trata de hacer patente el cinismo de un discurso moral de corte universalista que convive con prácticas que no son susceptibles de ser generalizadas. La pobreza, la desigualdad, la violencia y los desastres medioambientales ponen de manifiesto que la idea de que basta en educación con que los individuos sepan maximizar estratégicamente su interés resulta claramente insuficiente como propuesta moral de las sociedades democráticas.

Frente a ello es necesario destacar el diálogo entendido como un valor moral y una condición misma del ejercicio de la razón, y no sólo como un valor instrumental para la solución de un conflicto. El valor moral del diálogo deriva de entender que la razón no consiste ya en el descubrimiento de un orden de esencias fijas, sino que es el medio más inteligente para sobrevivir en un mundo donde no hay verdades definitivas ni preestablecidas. La democracia es el régimen político y social acorde con una visión contingentista y fragmentaria del mundo. Supone la afirmación de que somos seres sociales, que nuestra suerte está vinculada con la de los demás y que sólo hay acción inteligente en la medida en que incorporamos y hacemos nuestra la perspectiva de los demás. No se trata de que haya que renunciar al egoísmo bien entendido, sino de comprender que la inteligencia nos llama a una acción que comprende el punto de vista de los demás. El derrumbe del discurso ilustrado lo es también de la convicción de que es posible un acceso privilegiado a la verdad. El concepto tradicional de educación liberal estaba muy vinculado a la idea del individuo desarrollando su razón y acercándose cada vez más a la verdad. Esta era una concepción individualista alejada de la realidad de la producción del conocimiento. De ahí la necesidad de que se reconozca la importancia del diálogo público y colectivo como una consecuencia de que la verdad es el resultado del esfuerzo social y sostenido mediante el diálogo, y el contraste de ideas y opiniones. Se trata, por tanto, de afirmar como un objetivo educativo primordial el valor moral del diálogo y de los valores que el mismo conlleva. Supone la capacidad de escuchar y atender a los puntos de vista de otros pero también la de exponer los propios puntos de vista de manera razonada rechazando las actitudes dogmáticas e intransigentes. Además, conviene no olvidar la dimensión afectiva que el diálogo tiene, de modo que crea comunidad de objetivos e intereses contribuyendo mediante la superación del individualismo a la 
consolidación de un mayor sentido de la colectividad y comunidad. El verdadero diálogo, por otro lado, no es el que trata acerca de las cosas o del mundo como si fueran realidades acabadas, sino aquel que confia en la posibilidad de rehacer el mundo, esto es, busca la instauración de nuevas vías de acción. Así pues, supone la capacidad del sujeto de modelar y transformar la realidad, no tanto bajo la perspectiva del "yo quiero", cuanto del "nosotros deseamos".

Por otro lado, se ha señalado que ser un buen ciudadano implica no sólo derechos, sino también deberes y responsabilidades. La falta de asunción de responsabilidad de los ciudadanos respecto de la marcha de lo colectivo es uno de los rasgos de nuestra sociedad. En relación al concepto de responsabilidad es oportuno recordar que algunos de los estudios más importantes realizados en tiempos recientes en el campo de la ética (Hans Jonas, Peter Singer, ...) ponen de manifiesto que la responsabilidad no puede ser ya pensada bajo el principio de reciprocidad (yo no hago algo en la medida en que hay un otro pueda hacérmelo a $\mathrm{mi})$, sino que ha de incluir a todos aquellos a los que mi acción, $u$ omisión, pueda afectar. Jonas, ampliando el concepto tradicional de responsabilidad, entiende que ésta está vinculada con el poder. A mayor poder sobre los demás, mayor responsabilidad. El poder de los seres humanos en la era de la civilización tecnológica (más de unos que de otros) ha crecido exponencialmente y carece de precedentes. Por tanto, también lo ha hecho la responsabilidad, y ésta se extiende más allá de nuestros coetáneos hacia la de las generaciones futuras cuyo entorno tenemos el poder de modelar de manera muy significativa. Desde esta perspectiva, se ha señalado, los seres humanos no somos los dueños de este planeta sino sus gestores temporales que tenemos la responsabilidad de trasmitir a nuestros descendientes en condiciones que les permitan una libertad al menos tan amplia como la nuestra. Somos responsables ante las futuras generaciones del legado trasmitido.

Se entiende, por tanto, que el sistema educativo debe perseguir el desarrollo de actitudes responsables y comprometidas con la defensa del medio ambiente. Ésta debe incluir la crítica hacia un modo de vida consumista y modelos de desarrollo basados en la explotación abusiva e indiscriminada de los recursos naturales. Que los alumnos aprecien y sean sensibles hacia un entorno limpio y cuidado, que consideren valiosas otras formas de vida no humana, que muestren interés por informarse sobre las consecuencias negativas para el entorno de los comportamientos humanos, han de ser objetivos deseables del sistema educativo. En definitiva, lo que se quiere señalar es que la defensa y promoción de los valores medioambientales no es una cuestión privada. Es una consecuencia de un análisis racional y moral del ejercicio de la profesión docente en el marco de las sociedades postindustriales. La objeción de que ésta es una cuestión privada personal, que la docencia sólo compromete con la divulgación del conocimiento resulta un análisis erróneo, pues, como ya hemos puesto de manifiesto, los valores guían el 
RIS

REVISTA INTERNACIONAL DE SOCIOLOCIA

№ 34, Enero-Abril, 2003

CARLOS MOUCÁN RIVERO

conocimiento en la misma medida en que el avance científico-técnico guía los valores, y el ejercicio de la profesión docente supone un compromiso moral, no ya con la verdad considerada en abstracto, sino con los valores de la democracia: igualdad, libertad, responsabilidad ciudadana, etc.. de los que el profesor no puede abdicar. Y la sostenibilidad de nuestro sistema de vida es un problema que atañe de manera central a los valores de la democracia, pues el hecho de que la forma en que vivimos los occidentales no es generalizable pone en cuestión el valor de la igualdad.

Por otro lado, la igualdad ya no puede ser, como sí lo fue para los ilustrados, un recurso teórico que se asienta sobre la ignorancia, sea o no deliberada, de las profundas desigualdades, sobre las que se erige nuestro sistema de vida. La pobreza de grandes capas de la población mundial, la existencia de un orden económico y político en el ámbito internacional sobre relaciones asimétricas de poder, no son realidades que podamos hoy en día ignorar, y sobre las que tampoco somos inocentes. La globalización, entendida como un hecho, pone de manifiesto las interacciones que constituyen la realidad planetaria del ser humano. De ahí que haya de ser un objetivo importante del sistema educativo el desarrollo de una sensibilidad hacia todos los tipos de desigualdad, no sólo a escala local o nacional, sino también en el ámbito internacional. Formar ciudadanos en el seno de la democracia exige eliminar la indiferencia ante "la" suerte de los demás e interesarse por la de los más desfavorecidos. Puesto que es necesario empezar por las realidades más cercanas, es especialmente inadmisible en el ámbito educativo la existencia de actitudes que supongan la marginación o la exclusión sobre la base de la situación desfavorable de otros.

\section{CONCLUSIONES}

En la perspectiva liberal ilustrada, el profesor entendía que su tarea estaba exclusivamente comprometida con el conocimiento, y que este compromiso suponía al mismo tiempo una contribución al bien moral y a la justicia política. La crisis postmoderna de la educación liberal ha supuesto el "desencantamiento" de la ética de la profesión docente provocando, de manera general, reacciones, que, o bien ponen al docente al servicio de valores morales que le son impuestos desde fuera (posiciones libertarias y neoliberales), o bien reducen al mínimo su compromiso con la extensión de los valores cívicos. Frente a la crisis moral y política de la profesión docente, $\mathrm{y}$ frente a aquellas interpretaciones que han desplazado el compromiso moral y político como propio de concepciones doctrinarias ya pretéritas, $\mathrm{y}$ han relegado la responsabilidad de la promoción de valores morales al ámbito de la privacidad, lo que se ha querido defender es el carácter político de la tarea 
docente, la necesidad de redefinir este perfil profesional desde una perspectiva democrática que realza la importancia de la tarea que el sistema de enseñanza bajo control pública, y por ello el profesorado, tiene para el mantenimiento y la profundización en la democracia. Este compromiso moral no supone anular el papel decisorio en materia moral de los otros agentes educativos, singularmente la familia y el Estado, pero sí indica límites, al mismo tiempo que señala el terreno donde unos y otros pueden converger: el de la promoción de los valores acordes con una moral democrática. Esta no es una moral de mínimos, sino una moral pública defensora de valores que consolidan logros históricos, y que aspira a la transformación social mediante la profundización en los valores heredados de la tradición ilustrada: libertad, igualdad y solidaridad. Esta redefinición del carácter político de la profesión docente supone importantes modificaciones y transformaciones en diversos aspectos del sistema educativo.

\section{BIBLIOGRAFÍA}

ARENDT, H. (1996), "La crisis en la educación", Entre el pasado y el futuro, Barcelona, Península.

BAHMUELLER, Ch. (coord.) (año?), A Framework for civic Education. Center for civic education y la página web www.civnet.org.

BERKOWITZ, P. (2001), El liberalismo y la virtud, Barcelona, Andrés Bello.

DEL AGUILA, R. (2000), La senda del mal, Barcelona, Taurus.

FLATHMAN, R. (1998), "It all depends”, Political Theory, n² 26, vol.1, pp. 81-84.

FLATHMAN, R.E. (1996), "Liberal versus civic, republican, democratic, and other vocational educations", Political Theory, vol. 24, n 1, pp. 4-32.

FRIEDMAN, M. (1980), La libertad de elegir. Hacia un nuevo liberalismo económico, Barcelona. Grijalbo.

GALSTON, W. (1991), Liberal Purposes, Cambridge, Cambridge University

GIMENO SACRISTÁN, J. (1998), "Nuevos liberales y viejos conservadores ante la educación", en F. Álvarez Uría et al., Neoliberalismo versus Democracia, Ed. La piqueta.

GIROUX, H.A. (1993), La escuela y la lucha por la ciudadania, México, Siglo XXI.

GUTMANN, A. (1987), Democratic Education, Princenton, Princeton University Press.

HIRST, P. (1982), "La educación liberal y la naturaleza del conocimiento”, Educación y desarrollo de la razón, Madrid, Narcea. 
RIS

REVISTA INTERNACIONAL DE SOCIOLOCIA

№34, Enero-Abril, 2003

CARLOS MOUGÁN RIVERO

HUMBOLDT, W.V. (1998), Los limites de la acción del estado, Madrid, Tecnos.

KIMBALL, B. (1995), Orators and Philosophers. A History of the Idea of Liberal Education, The College Board, Nueva York.

MOUGÁN, C. (2000), "Liberalismo político y educación cívica", Alfa, nº 8, pp.91-121.

POSTMAN, N. (1999), El fin de la educación, Barcelona, Octaedro.

RAWLS, J. (1996), Liberalismo politico, Barcelona, Crítica.

SHKLAR, J. (1989), “The liberalism of Fear", Liberalism and the moral life, ed. Nancy Roseublum, Cambridge, Mass, Harvad University Press.

TEDESCO, J.C. (1995), El nuevo pacto educativo, Madrid, Ed. Anaya.

THIESSEN, E.J. (1993), Teaching for Commitment. Liberal Education, Indoctrination and Christian Nurture, MacGill-Queen's University Press.

(1995), "Liberal Education, Public Schools, and the Embarrasment of Teaching for Commitment", Yearbook, Philosophy of Education, University of Ilinois (www.ed.uiuc.edu/EPS/PESyearbook).

TORRES, J. (2001), Educación en tiempos de neoliberalismo, Madrid, Morata. 